\title{
Dominant Strategic Trade Policy
}

\author{
Valentin Melnik \\ Department of Applied informatics and modeling \\ Pskov State University \\ Pskov, Russia \\ melnikvn@yahoo.com
}

\begin{abstract}
In implementing trade policy measures, governments usually select from a range of instruments including quotas, subsidies (explicit or implicit) and tariffs. In this paper we consider the potential gain of a government pursuing a two-part trade policy: an import license for entry, along with a per-unit tariff on imports. The model is a threestep game between home and foreign countries in the Cournot duopoly. The paper demonstrates that two-part trade policy is dominant.
\end{abstract}

Keywords - strategic trade policy, Nash equilibrium, tariffs, quotas, subsidies.

\section{INTRODUCTION}

Surveys have repeatedly shown strong support among economists for free trade policies who state that "The consensus among mainstream economists on the desirability of free trade remains almost universal". Despite this, trade barriers still exist and generally take the form of tariffs, quotas, non-tariff barriers and voluntary export restraints (VER's). In this paper, we consider the implementation of a two-part trade policy. The basic model is a two level game. At the first level each government implements its trade policy and at the second level, producers in both countries behave as Cournot competitors.

We use our model to demonstrate that a two part trade policy offers the authorities a superior outcome over a one part strategy and that a one part trade policy, consisting of a simple quota or simple tariff, is simply a special case of a two part policy. We show that the effectiveness of the two part trade strategy depends on the number of competing firms in the market, the degree of heterogeneity between cost functions, the degree of convexity of cost functions (and therefore which firms the policy will apply to) and the aims of the governments implementing the trade policy.

The classical problem in the theory of the policies of international trade concerns the effect of the tariffs and quotas or the effect of a variety of possible policies. In absolutely competitive models of trade, tariffs and quotas are usually equivalent, that is the effect of the tariff can be duplicated by the accordingly chose model of quota. As it is stated by Bhagwati [1], it will not be true at imperfect competition. He has demonstrated, that the tariffs dominate above the quotas, when there is an imperfect competition in home market. It can be explained by the fact that the keen response of foreign firms at the quota is more exact, than at the tariff. Thus, the quota in comparison with the tariff raises monopolistic force of internal firms. Anderson [2] considered the duopoly model and showed, that under the certain conditions quotas tend to lower competition. Krishna [3] has shown in model of a Bertrand, that the quota constrains the ability of firms to compete effectively, when the goods are perfect substitutes. Accordingly, we could expect some interesting comparisons between the tariffs and quotas as strategic instrumental means of trade policy. The analysis of the quotas at oligopoly give additional penetrations.

Brander and Spencer [4] were the first to use an oligopoly model to explain export subsidies. They showed that when one home firm and one foreign firm produce a homogenous product and compete in a third market, an export subsidy is optimal in shifting monopoly rent from foreign to domestic firms. They demonstrate this finding in a Cournot model with constant returns to scale technology. Eaton and Grossman [5] extend paper [4] by replicating their analysis in a Bertrand model and show that a government in one of the first two countries has a unilateral incentive to impose export taxes (not subsidies) on its home firm. This tax allows the home firm to commit to a higher price (or act as a Stackelberg leader) and thus obtain higher profits for its country. Then, they confirm that when the governments of the first two countries can both credibly pre-commit to a policy, exporting governments optimally set taxes (not subsidies) in a subgame perfect Nash equilibrium under the Bertrand market structure. Eaton and Grossman [5] therefore broke

Online ISSN 2256-070X

https://doi.org/10.17770/etr2021vol2.6542

(C) 2021 Valentin Melnik.

Published by Rezekne Academy of Technologies.

This is an open access article under the Creative Commons Attribution 4.0 International License. 
new ground by showing that the outcome of policy is sensitive to the nature of competition between firms.

The two-part trade policy provides for considering the import license for an entrance alongside with the tariff for the unit of import. Such policy was first introduced by Oi [6] in the classical analysis of a price dilemma of Disneyland. Philips [7] and Wilson [8] also considered the examples of nonlinear assigning of the prices. For the case of sole market with homogeneous functions of costs, Fuerst and Kim [9] have considered the two-part trade policy at complete, but imperfect information. In the market model of one country with homogeneous functions of costs they have found conditions, when the optimal two-part trade policy dominates above the simple tariff and simple quota. It is also fair both for a government, which is interested only in maximization of the income, and for benevolent government interested in internal welfare. The effect arises because the large payment for the import license imposes a smaller amount of distortions, than tariff. A government can reach the neutral income, reducing current tariffs and reimbursing the lost incomes by the payment for the license. With inhomogeneous functions of costs Fuerst and Kim [9] have considered numerical examples, which also have shown advantage of the two-part trade policy.

\section{MATERIALS AND METHODS}

In this paper we consider a two part trade policy in a model with reciprocal markets. In the model, there are two countries with $N$ domestic firms and $M$ foreign firms producing a homogenous product. Suppose $q_{i}$ is the output of the $i$ firm for the domestic market and $q_{i}^{*}$ is the level of exports of the $i$ firm to the foreign market. Similarly, suppose $v_{j}$ that is the level of exports to the domestic market by a foreign firm, $j$ and $v_{j}^{*}$ is the output of firm $j$ for the foreign market. The total sales in both the home market and the foreign market, $Q$ and $Q^{*}$ respectively, as in (1) and (2).

$$
\begin{gathered}
Q=\sum_{i=1}^{N} q_{i}+\sum_{j=1}^{M} v_{j} \\
Q^{*}=\sum_{i=1}^{N} q_{i}^{*}+\sum_{j=1}^{M} v_{j}^{*}
\end{gathered}
$$

Demand is a function of price and firms face the usual inverse demand curves in both markets. Specifically, in the home market we have $P(Q)$ and in the foreign market we have $P^{*}\left(Q^{*}\right)$ where $p, p^{*} \in C^{2}, p^{\prime}<0,\left(p^{*}\right)^{\prime}<0$. It is also known $c_{i}\left(q_{i}\right)$ is the cost function of the $i$ home firm and $c_{j}^{*}\left(q_{j}^{*}\right)$ is the cost function of the $j$ foreign firm, where $c_{i}, c_{j}^{*} \in C^{2}$, and $c_{i}^{\prime}>0, c_{i}^{\prime \prime}>0,\left(c_{j}^{*}\right)^{\prime}>0,\left(c_{j}^{*}\right)^{\prime \prime}>0$. ( $C^{2}$ - set of twice continuously differentiable functions).

We assume that firms aim to maximise profit and their output decisions are therefore guided by their profit functions, as in (3) and (4).

$$
\begin{gathered}
\pi_{i}=p(Q) q_{i}-c_{i}\left(q_{i}+q_{i}^{*}\right)+p^{*}\left(Q^{*}\right) q_{i}^{*}-t^{*} q_{i}^{*}- \\
e^{*}, \quad i=1, \ldots N
\end{gathered}
$$

$$
\begin{gathered}
\pi_{j}^{*}=p^{*}\left(Q^{*}\right) v_{j}^{*}-c_{j}^{*}\left(v_{j}+v_{j}^{*}\right)+p(Q) v_{j}-t v_{j}- \\
e, j=1, \ldots M
\end{gathered}
$$

In (3) and (4) $e$ and $e^{*}$ are payments for the license to home and foreign governments respectively and $t$ and $t^{*}$ are the tariff per unit of sales imposed on home and foreign firms respectively.

We designate the two part trade policies of the home and foreign governments by the vectors, as in (5) and (6).

$$
\begin{aligned}
z & =(e, \bar{v}, t) \\
z^{*} & =\left(e^{*}, \bar{q}, t^{*}\right)
\end{aligned}
$$

In (5) and (6) $\bar{q}, \bar{v}$ are the quotas on home and foreign. This description of trade policy incorporates the standard quota and tariff policy. For example, simple quota is (7). Similarly, a simple tariff is (8).

$$
\begin{aligned}
& z=z_{v} \equiv(e, \bar{v}, 0) \\
& z=z_{t} \equiv(0, \infty, t)
\end{aligned}
$$

In the analysis of strategic trade policy, the third-market model is well known [4], [5]. In this model one or more firms from a domestic country and one or more firms from a foreign country compete only in the third market. Firms therefore produce only for export to the third market. This simplification is very useful in analysing the strategic effects of trade policy since neither government (domestic nor foreign) can implement direct trade policies (tariffs or quotas) which impact upon the behaviour of firms in the third market. The natural choice of policy instrument is therefore an export subsidy which gives the domestic firm a competitive advantage over its foreign rival. However, in this paper we show that a two-part trade policy, consisting of a negative tariff (subsidy) and a quota license, is optimal.

\section{RESULTS AND DISCUSSION}

We construct a two stage model; in keeping with much of the literature on strategic trade policy [4]. We analyse behaviour in a Cournot model. In the first stage of our model, the domestic government implements a two-part trade policy for domestic firms. At the second stage an interior and an exterior firm simultaneously choose an output level (or export) for the third market. In the second stage we use an inverse induction to find a perfect subgame Nash equilibrium. We then consider Nash equilibrium between governments in the first stage and we show that their respective trade policies impact on output levels of firms in the second stage. The payoff functions of firms $i$, $j(i=1, \ldots N, j=1 \ldots M)$ are defined by relations, as in (9) and (10).

$$
\begin{gathered}
\pi_{i}=p(Q) q_{i}-c_{i}\left(q_{i}\right)-t q_{i}-e \\
\pi_{j}^{*}=p(Q) v_{j}-c_{j}^{*}\left(v_{j}\right)-t^{*} v_{j}-e^{*}
\end{gathered}
$$


In (9) and (10) $e$ and $e^{*}$ are the payments for the license to home and foreign government respectively, $t$ and $t^{*}$ are the tariff per unit of production imposed on home and foreign firms respectively. We also impose a restriction on the model that cost functions are homogenous and are of the form $c_{i}(q)=c(q), \forall i ; c_{j}^{*}(v)=c^{*}(v), \forall j$.

By stage 2, tariffs $t$ and $t^{*}$ have been predetermined in stage 1 and are therefore treated as exogenous. The first order conditions associated with maximization of (9) and (10), as in (11) and (12).

$$
\begin{gathered}
\frac{\partial \pi_{i}}{\partial q_{i}}=p^{\prime} q_{i}+p-c^{\prime}-t=0 \\
\frac{\partial \pi_{j}^{*}}{\partial v_{j}}=p^{\prime} v_{j}+p-\left(c^{*}\right)^{\prime}-t^{*}=0
\end{gathered}
$$

The second order conditions associated with maximization of (9) and (10), as in (13) and (14).

$$
\begin{gathered}
\frac{\partial^{2} \pi_{i}}{\partial q_{i}^{2}}=p^{\prime \prime} q_{i}+p^{\prime}+p^{\prime}-c^{\prime \prime}<0 \\
\frac{\partial^{2} \pi_{j}^{*}}{\partial v_{i}^{2}}=p^{\prime \prime} v_{i}+p^{\prime}+p^{\prime}-\left(c^{*}\right)^{\prime \prime}<0
\end{gathered}
$$

The first order condition (11), (12) makes it clear that a Cournot equilibrium is a Nash equilibrium in outputs since (11), (12) is implied by the Nash condition for the case in which each player's strategy set is simply the set of possible output quantities that might produce in a one-shot simultaneous-move game. The Cournot equilibrium therefore has the same 'no surprises' rationality property that any Nash equilibrium has. The first order condition (11), (12) could be solved in principle for the profitmaximizing choice of for any given set of output choices by the other firms. This resulting implicit function is the reaction function or best-response function. The common intersection of the best-response functions (one for each firm) is the Cournot equilibrium.

An additional regularity condition that turns out to be central to the characterization of the Cournot equilibrium, as in (15) and (16).

$$
\begin{gathered}
\frac{\partial^{2} \pi_{i}}{\partial q_{i} \partial v_{j}}=p^{\prime \prime} q_{i}+p^{\prime}<0 \\
\frac{\partial^{2} \pi_{j}^{*}}{\partial v_{j} \partial q_{i}}=p^{\prime \prime} v_{j}+p^{\prime}<0
\end{gathered}
$$

Condition (15), (16) is linked to many properties of the Cournot model. It is the so-called Hahn stability condition for certain proposed dynamic adjustment mechanisms and it implies that each firm's marginal revenue declines as the output of any other firm rises. (Note, however, that the pure Cournot model is a one-shot static game with no real-time dynamics. Any proposed dynamic adjustment is an extension to the model). Presuming that second order conditions are globally satisfied, global satisfaction of (15), (16) in this context is also the Gale-Nikaido condition for uniqueness of the Cournot equilibrium. Condition (15), (16) also ensures that the various comparative static properties of the model are 'well-behaved'.

Most importantly, condition (15), (16) implies that strategy variables $q_{i}$ and $v_{j}$, are strategic substitutes. If $\frac{\partial^{2} \pi_{i}}{\partial q_{i} \partial v_{j}}<0, \forall i$, this implies that the marginal value, $\frac{\partial \pi_{i}}{\partial q_{i}}$ of increasing firm $i$ strategy variable, decreases when the strategy variable of a rival increases.

The solution to the first order conditions will yield $q_{1}$ and $v_{1}$ as functions of tariffs $t$ and $t^{*}$. The comparative static effects $\frac{\partial q_{1}}{\partial t}, \frac{\partial q_{1}}{\partial t^{*}}, \frac{\partial v_{1}}{\partial t}, \frac{\partial v_{1}}{\partial t^{*}}$ can be obtained by totally differentiating the first order conditions (11), (12) with respect to $q_{1}, v_{1}, t$ and $t^{*}$, as in (17) and (18).

$$
\begin{aligned}
& \left\{\begin{array}{l}
\frac{\partial^{2} \pi_{1}}{\partial q_{1}^{2}} \cdot \frac{\partial q_{1}}{\partial t}+\frac{\partial^{2} \pi_{1}}{\partial q_{1} \partial v_{1}} \cdot \frac{\partial v_{1}}{\partial t}=1 \\
\frac{\partial^{2} \pi_{1}^{*}}{\partial v_{1} \partial q_{1}} \cdot \frac{\partial q_{1}}{\partial t}+\frac{\partial^{2} \pi_{1}^{*}}{\partial v_{1}^{2}} \cdot \frac{\partial v_{1}}{\partial t}=0
\end{array}\right. \\
& \left\{\begin{array}{l}
\frac{\partial^{2} \pi_{1}}{\partial q_{1}^{2}} \cdot \frac{\partial q_{1}}{\partial t^{*}}+\frac{\partial^{2} \pi_{1}}{\partial q_{1} \partial v_{1}} \cdot \frac{\partial v_{1}}{\partial t^{*}}=0 \\
\frac{\partial^{2} \pi_{1}^{*}}{\partial v_{1} \partial q_{1}} \cdot \frac{\partial q_{1}}{\partial t^{*}}+\frac{\partial^{2} \pi_{1}^{*}}{\partial v_{1}^{2}} \cdot \frac{\partial v_{1}}{\partial t^{*}}=1
\end{array}\right.
\end{aligned}
$$

These equations can be solved using Cramer's rule, as in (19) - (22).

$$
\begin{gathered}
\frac{\partial q_{1}}{\partial t}=\frac{1}{D} \cdot \frac{\partial^{2} \pi_{1}^{*}}{\partial v_{1}^{2}} \\
\frac{\partial v_{1}}{\partial t}=-\frac{1}{D} \cdot \frac{\partial^{2} \pi_{1}^{*}}{\partial v_{1} \partial q_{1}} \\
\frac{\partial q_{1}}{\partial t^{*}}=-\frac{1}{D} \cdot \frac{\partial^{2} \pi_{1}}{\partial q_{1} \partial v_{1}} \\
\frac{\partial q_{1}}{\partial t}=\frac{1}{D} \cdot \frac{\partial^{2} \pi_{1}}{\partial q_{1}^{2}}
\end{gathered}
$$

$D$ is the determinant of the left-hand matrix in (17) and (18), as in (23).

$$
D=\frac{\partial^{2} \pi_{1}}{\partial q_{1}^{2}} \cdot \frac{\partial^{2} \pi_{1}^{*}}{\partial v_{1}^{2}}-\frac{\partial^{2} \pi_{1}}{\partial q_{1} \partial v_{1}} \cdot \frac{\partial^{2} \pi_{1}^{*}}{\partial v_{1} \partial q_{1}}>0
$$

From (13) - (16) we get the conditions, as in (24).

$$
\frac{\partial q_{1}}{\partial t}<0, \frac{\partial q_{1}}{\partial t^{*}}>0, \frac{\partial v_{1}}{\partial t}>0, \frac{\partial v_{1}}{\partial t^{*}}<0
$$

Thus we have proved a Lemma.

\section{Lemma 1. Suppose that:}

1) the cost functions $c_{1}(q)$ and $c_{1}^{*}(q)$ are twice continuously differentiable and convex, for any $q \geq 0$; 
2) the inverse demand curve $p(Q)$ is twice continuously differentiable and decrease, for any $Q \geq 0$;

3) the function $p(q+\widetilde{Q}) \cdot q$ is concave in $q$, for any $\widetilde{Q} \geq$ 0 . Then in the third-market model at two-part trade policy implies (23).

Corollary 1. $\frac{\partial \mathrm{v}_{1}}{\partial \mathrm{t}}=\alpha \frac{\partial \mathrm{q}_{1}}{\partial \mathrm{t}} \quad$, where $\alpha \in(-1,0)$ and $\frac{\partial \mathrm{q}_{1}}{\partial \mathrm{t}^{*}}=\beta \frac{\partial \mathrm{v}_{1}}{\partial \mathrm{t}^{*}}$, where $\beta \in(-1,0)$.

Proof: Let $\tilde{q}_{1}\left(v_{1}\right)$ and $\tilde{v}_{1}\left(q_{1}\right)$ be the domestic firm's best response and the foreign firm's best response respectively.

Using conditions 1)-3) of Lemma 1 the first-order condition, as in (25).

$$
\frac{\partial \widetilde{v_{1}}}{\partial q_{1}}=-\frac{p^{\prime \prime} \cdot v_{1}+p^{\prime}}{2 p^{\prime}+p^{\prime \prime} \cdot v_{1}-\left(c_{1}^{*}\right)^{\prime \prime}}=\alpha \epsilon(-1,0)
$$

Next, we have conditions, as in (26).

$$
\frac{\partial v_{1}}{\partial t}=\frac{\partial \widetilde{v_{1}}}{\partial q_{1}} \cdot \frac{\partial q_{1}}{\partial t}=\alpha \frac{\partial q_{1}}{\partial t}
$$

It is similarly proved that $\frac{\partial q_{1}}{\partial t^{*}}=\beta \cdot \frac{\partial q_{1}}{\partial t}$, where $\beta \in$ $(-1,0)$. Proved.

As the basic model we shall consider the two stage game with complete, but imperfect information. In the first stage, players 1 and 2 (the home and foreign governments respectively) simultaneously choose their strategy and inform their respective home and foreign firms (players 3 and 4) which in the second stage simultaneously choose their strategy.

Let's designate $x_{1}=(e, \bar{v}, t) \in X_{1}$ and $x_{2}=$ $\left(e^{*}, \bar{q}, t^{*}\right) \in X_{2}$ as the strategies of the first and the second players respectively, where $X_{k}=R_{+} \times R_{+} \times R$ is the set of strategy $k$ of the player $(k=1,2)$. Let $x_{3}=q_{1} \in X_{3}$ be the strategy of player 3 and $x_{4}=v_{1} \in X_{4}$ be the strategy of player $4, X_{i}=R_{+} \times R_{+}$is the set of strategy $i$ of the player $(i=1,2)$. Let's designate $x \in X=X_{1} \times X_{2} \times X_{3} \times$ $X_{4}$.

Let's define the functions, as in (27) - (30).

$$
\begin{gathered}
f_{1}(x) \equiv p \cdot q_{1}\left(t, t^{*}\right)-c\left(q_{1}\left(t, t^{*}\right)\right) \\
f_{2}(x) \equiv p \cdot v_{1}\left(t, t^{*}\right)-c^{*}\left(v_{1}\left(t, t^{*}\right)\right) \\
f_{3}(x) \equiv \pi_{1}(x) \\
f_{4}(x) \equiv \pi_{1}^{*}(x)
\end{gathered}
$$

Then it is possible to define the two-stage game for 4 players with complete, but imperfect, information, as in (31).

$$
\Gamma=\left\langle I=\{1,2.3 .4\},\left\{X_{i}\right\}_{i \in I},\left\{f_{i}(x)\right\}_{i \in I}\right\rangle
$$

The following existence theorem of Nash equilibrium in game $\Gamma$ is fair.

Theorem 1. Suppose that:

1) the cost functions $c_{1}(q)$ and $c_{1}^{*}(q)$ are twice continuously differentiable and convex, for any $q \geq 0$;

2) the inverse demand curve $p(Q)$ is twice continuously differentiable and decrease, for any $Q \geq 0$;

3) the function $p(q+\widetilde{Q}) \cdot q$ is concave in $q$, for any $\widetilde{Q} \geq$ 0 ;

4) $\exists \widetilde{\mathrm{Q}}$, that $\mathrm{p}(\mathrm{Q})=0, \forall \mathrm{Q} \geq \widetilde{\mathrm{Q}}$,

then in game $\Gamma$ there exists a perfect subgame Nash equilibrium.

Proof: I) Taking into account the imposing of quota by $q_{1}$ and $v_{1}$ we get that $q_{1} \in[0, \bar{q}], v_{1} \in[0, \bar{v}]$. Thus maximization $\pi_{1}$ by $q_{1}$ can be considered as a compact set $X_{3}=[0, \bar{q}]$ and maximization $\pi_{1}^{*}$ by $v_{1}$ by is a compact set $X_{4}=[0, \bar{v}]$.

II) By conditions 1), 2) of Theorem 1. Functions $\pi_{1}\left(q_{1}, v_{1}\right)$ and $\pi_{1}^{*}\left(q_{1}, v_{1}\right)$ are continuous.

III) As according to the conditions 1) - 3) of Theorem 1. the theorems guarantee the conditions, as in (32) and (33).

$$
\begin{gathered}
\frac{\partial^{2} \pi_{1}}{\partial q_{1}^{2}}=p^{\prime \prime} q_{i}+2 p^{\prime}-c^{\prime \prime}<0 \\
\frac{\partial^{2} \pi_{1}^{*}}{\partial v_{1}^{2}}=p^{\prime \prime} v_{i}+2 p^{\prime}-\left(c^{*}\right)^{\prime \prime}<0
\end{gathered}
$$

The conditions (32), (33) guarantee concavity of the functions $\pi_{1}\left(q_{1}, v_{1}\right)$ and $\pi_{1}^{*}\left(q_{1}, v_{1}\right)$.

IV) Thus, from I), II), III) and the Nash theorem implies that there exists a Cournot equilibrium $\left\langle q_{1}^{0}\left(t, t^{*}\right), v_{1}^{0}\left(t, t^{*}\right)\right\rangle$ in the second stage of the game.

To see how this result is obtained, we first consider the first stage of the game between governments. We need to demonstrate that theorem 1 also guarantees the existence of a Nash equilibrium in the first stage of the game, and consequently the existence of the perfect subgame Nash equilibrium, which determines the optimum two-part trade policy.

V) To do this we first demonstrate that the problem of maximization $f_{1}(x)$ by $t$ can be considered as a segment (compact set) $X_{1}=\left[t_{\mathrm{H}}, t_{\mathrm{B}}\right]$ and the problem of maximization $f_{2}(x)$ by $t^{*}$ can be considered as a segment (compact set) $X_{2}=\left[t_{\mathrm{H}}^{*}, t_{\mathrm{B}}^{*}\right]$. This fact emerges immediately from the continuity and limitation of the functions $q_{1}\left(t, t^{*}\right)$ and $v_{1}\left(t, t^{*}\right)$.

VI) Since $p(Q) \in C^{2} ; c(q) \in C^{2}$ and $c^{*}(v) \in C^{2}$, then the functions $f_{1}\left(t, t^{*}\right)$ and $f_{2}\left(t, t^{*}\right)$ are continuous.

VII) Further, we can prove concavity of the functions $f_{1}\left(t, t^{*}\right)$ and $f_{2}\left(t, t^{*}\right)$ by $t$ and $t^{*}$. 
Environment. Technology. Resources. Rezekne, Latvia Proceedings of the $13^{\text {th }}$ International Scientific and Practical Conference. Volume 2, 106-111 (34).

We differentiate function $f_{1}\left(t, t^{*}\right)$ twice by $t$, as in

$$
\begin{gathered}
\frac{\partial^{2} f_{1}\left(t, t^{*}\right)}{\partial t^{2}}=\left(p^{\prime \prime} q_{1}+2 p^{\prime}-c^{\prime \prime}\right) \cdot\left(\frac{\partial q_{1}}{\partial t}\right)^{2}++2\left(p^{\prime \prime} \cdot q_{1}+\right. \\
\left.p^{\prime}\right) \cdot \frac{\partial q_{1}}{\partial t} \cdot \frac{\partial v_{1}}{\partial t}+p^{\prime \prime} \cdot q_{1} \cdot\left(\frac{\partial v_{1}}{\partial t}\right)^{2}
\end{gathered}
$$

Using Lemma 1 and Corollary 1 and if $p^{\prime \prime}<0$, then the estimation is fair, as in (35).

$$
\begin{gathered}
\frac{\partial^{2} f_{1}\left(t, t^{*}\right)}{\partial t^{2}}=\left(p^{\prime \prime} v_{1} \cdot(\alpha+1)^{2}+2 p^{\prime} \cdot(1+\alpha)-\right. \\
\left.-c^{\prime \prime}\right)\left(\frac{\partial q_{1}}{\partial t}\right)^{2}<0
\end{gathered}
$$

if $p^{\prime \prime} \geq 0$ then the estimation is fair, as in (36).

$$
\begin{gathered}
\frac{\partial^{2} f_{1}\left(t, t^{*}\right)}{\partial t^{2}}=\left(p^{\prime \prime} v_{1} \cdot(\alpha+1)^{2}+2 p^{\prime} \cdot(1+\alpha)-\right. \\
\left.-c^{\prime \prime}\right)\left(\frac{\partial q_{1}}{\partial t}\right)^{2} \leq\left(p^{\prime \prime} \cdot q+p^{\prime}\right) \cdot(1+\alpha)+ \\
+p^{\prime}(1+\alpha)-c^{\prime \prime}<0
\end{gathered}
$$

The function $f_{1}\left(t, t^{*}\right)$ is therefore concave by $t$. Similarly we obtain a concavity for the function $f_{2}\left(t, t^{*}\right)$ by $t^{*}$.

VIII) So, from V), VI) and VII) and the Nash theorem implies that there is Nash equilibrium in the first stage of the game $\left(t^{0}, t^{* 0}\right)$. It also follows from IV) and VIII) that in the game $\Gamma$, there exists perfect subgame Nash equilibrium, as in (37).

$$
\begin{gathered}
X^{0}=\left\langle\left(e^{0}, \bar{q}^{0}, t^{0}\right),\left(e^{* 0}, \bar{v}^{0}, t^{* 0}\right), q_{1}^{0}\left(t, t^{*}\right), v_{1}^{0}\left(t, t^{*}\right)\right\rangle \\
e^{* 0}=p\left(q_{1}^{0}\left(t^{0}, t^{* 0}\right)+v_{1}^{0}\left(t, t^{* 0}\right)\right) \cdot q_{1}^{0}\left(t^{0}, t^{* 0}\right)- \\
c\left(q_{1}^{0}\left(t^{0}, t^{* 0}\right)\right)-t^{0} \cdot q_{1}^{0}\left(t^{0}, t^{* 0}\right) \\
e^{0}=p\left(q_{1}^{0}\left(t^{0}, t^{* 0}\right)+v_{1}^{0}\left(t, t^{* 0}\right)\right) \cdot v_{1}^{0}\left(t^{0}, t^{* 0}\right)- \\
c^{*}\left(v_{1}^{0}\left(t^{0}, t^{* 0}\right)\right)-t^{0} \cdot v_{1}^{0}\left(t^{0}, t^{* 0}\right) \\
\bar{v}^{0}=v_{1}^{0}\left(t^{0}, t^{* 0}\right), \bar{q}^{0}=q_{1}^{0}\left(t^{0}, t^{* 0}\right)
\end{gathered}
$$

Proved.

From theorem 1 we derive a remarkable corollary.

Corollary 2. In the third-market model the optimum twopart tariff $t$ which maximizes the government's revenue is negative, that is, a subsidy, and the optimum payment for the license is equal to the level of foreign profits. below.

We consider the third market model in Example 1

Example 1. In this example we assume the existence of one market, two governments and two firms. We assume an inverse demand function of the form, as in (38).

$$
p(Q)=1-Q
$$

\begin{tabular}{|c|c|c|c|}
\hline & \multicolumn{3}{|c|}{ Home government } \\
\hline & & free trade & two-part trade \\
\hline 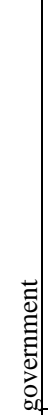 & 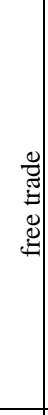 & $\begin{array}{l}G=0 ; G^{*}=0 \\
\pi=\frac{1}{9}\left(1-2 c+c^{*}\right)^{2} \\
\pi^{*}=\frac{1}{9}\left(1-2 c^{*}+c\right)^{2} \\
q=\frac{1}{3}\left(1-2 c+c^{*}\right) \\
q^{*}=\frac{1}{3}\left(1-2 c^{*}+c\right) \\
t=0 ; t^{*}=0 \\
e=0 ; e^{*}=0\end{array}$ & $\begin{array}{l}G=\frac{1}{8}\left(1-2 c+c^{*}\right)^{2} ; \\
G^{*}=0 ; \\
\pi=0 ; \\
\pi^{*}=\frac{1}{16}\left(1-3 c^{*}+2 c\right)^{2} ; \\
q=\frac{1}{2}\left(1-2 c+c^{*}\right) ; \\
q^{*}=\frac{1}{4}\left(1-3 c^{*}+2 c\right) ; \\
t=-\frac{1}{4}\left(1-2 c+c^{*}\right) ; \\
t^{*}=0 ; \\
e=\frac{1}{4}\left(1-2 c+c^{*}\right)^{2} ; \\
e^{*}=0 ;\end{array}$ \\
\hline $\begin{array}{l}\text { : } \\
0 \\
0 \\
0 \\
0\end{array}$ & 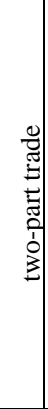 & $\begin{array}{l}G=0 ; \\
G^{*}=\frac{1}{8}\left(1-2 c^{*}+c\right)^{2} ; \\
\pi=\frac{1}{16}\left(1-3 c+2 c^{*}\right)^{2} ; \\
\pi^{*}=0 \\
q=\frac{1}{4}\left(1-3 c+2 c^{*}\right) ; \\
q^{*}=\frac{1}{2}\left(1-2 c^{*}+c\right) ; \\
t=0 ; \\
t^{*}=-\frac{1}{4}\left(1-2 c^{*}+c\right) ; \\
e=0 ; \\
e^{*}=\frac{1}{4}\left(1-2 c^{*}+c\right)^{2} ;\end{array}$ & $\begin{array}{l}G=\frac{2}{25}\left(1-3 c^{*}+2 c\right)^{2} ; \\
G^{*}=\frac{2}{25}\left(1-3 c+2 c^{*}\right)^{2} ; \\
\pi=0 ; \pi^{*}=0 ; \\
q=\frac{2}{5}\left(1-3 c^{*}+2 c\right) ; \\
q^{*}=\frac{2}{5}\left(1-3 c+2 c^{*}\right) ; \\
t=-\frac{1}{5}\left(1-3 c+2 c^{*}\right) ; \\
t^{*}=-\frac{1}{5}\left(1-3 c^{*}+2 c\right) ; \\
e=\frac{4}{25}\left(1-3 c^{*}+2 c\right) ; \\
e=\frac{4}{25}\left(1-3 c+2 c^{*}\right) ;\end{array}$ \\
\hline
\end{tabular}

The cost functions of home and foreign firms are given, as in (39).

$$
C(Q)=c \cdot q, C^{*}(q)=c^{*} \cdot q
$$

To derive the optimum two-part trade policy we apply the method of inverse induction. Thus we consider the various combinations of applying or not applying the twopart trade policies by different governments.

The outcomes are given in TABLE I which shows that the optimum two-part trade policy is the subsidy at the positive payment for the license.

TABLE I.

It is also interesting to note that if the two-part trade policy is applied by only one government, the optimum rate of subsidy is increased because of the home firm's relative advantage. A subsidy also encourages the home firm to act more aggressively because of the competitive advantage given by the subsidy. As a result it captures more its foreign rival's market and output of the rival therefore contracts. The optimal domestic subsidy moves the domestic firm to Stackelberg leader output level, while the foreign firm produces the Stackelberg follower output. In effect, the government is able to convert its first-mover advantage into an equivalent advantage for the domestic firm.

If the two-part policy is applied by both governments, their optimum policy still will be the subsidy at the optimal licensing fee is equal to the operating profits of the foreign firm. However, where the government aims to maximize welfare $\left(G+\pi_{1}\right.$ and $\left.G^{*}+\pi_{1}^{*}\right)$ a classic prisoner's dilemma situation emerges since both countries are in a worse position in a position as a result of implementing a strategic trade policy than if they both adopt free trade, yet each country has an incentive to deviate from the free trade option. 


\section{CONCLUSIONS}

In this paper we analyse the simultaneous use by government of quotas (and corresponding license fees) and tariffs. The use of quotas and tariffs as complements rather than substitutes enables us to identify a trade policy that dominates in terms of efficiency over other trade policy instruments. The qualitative outcomes of analysis depend on the type of government (whether it maximizes its revenue or public welfare), market structure and the cost structure of firms operating in the market.

We have shown that the two-part trade policy dominates the simple quota and simple tariff, and that the latter two are special cases of a two part trade policy.

We show that for the third-market model, the optimal two-part trade policy is a subsidy. For this case the analytical results (Lemma 1 and Theorem 1) are obtained. In this part of our paper we investigated the properties of cost functions and inverse demand functions which define the existence of optimal trade policy.

\section{REFERENCES}

[1] J. N. Bhagwati, “On the Equivalence of Teriffs and Quotas”, In Robert E. Baldwin et al. (ets), Trade, Growth and the Balance of Payments: Essays in Honor of Gottfried Haberler. Chicago: Rand McNally, 1965.

[2] J. E. Anderson, The Relative Inefficiency of Quotas. The MIT Press, 1988.

[3] K. Krishna, “Trade Restrictions as Facilitating Practices,” Journal of International Economics, vol. 26, pp. 251-270, 1989.

[4] J. A. Brander and B. J. Spencer, "Export subsidies and market share rivalry,” Journal of International Economics, vol. 18, pp. 83-100, 1985.

[5] J. H. Cassing and A.L. Hillman, "Political Influence Motives and the Choice between Tariffs and Quotas,” Journal of International Economics, vol. 19, pp. 279-290, 1985.

[6] W. Y. Oi, “A Disneyland Dilemma: Two-Part Tariffs for a Mickey Mouse Monopoly,” Quarterly Journal of Economics, vol. 85, pp. 77-90, 1971.

[7] L. Philips, The Economics of Price Discrimination. Cambridge University Press , 1983.

[8] R. B. Wilson, Nonlinear Pricing. Oxford University Press, 1993.

[9] T. S. Fuerst and K. H. Kim, “Two - Part Trade Policy under Imperfect Competition,” Review of International Economics vol. 5(1), pp. 63-71, 1997. 